\title{
SOBREVIVENDO À MANAUS MODERNA
}

\section{Rafaela Bastos de Oliveira *}

Com alguma frequência, ainda em nossos dias, através das mídias: sites, jornais televisionados ou impressos, há menções em torno das disputas sobre o uso do espaço conhecido Manaus Moderna, um local que abrange porto, feiras, lojas das mais diversos artigos, barracas improvisadas de vendedores ambulantes às margens do Rio Negro e suas proximidades, no Centro da cidade de Manaus. O trabalho da professora Patrícia Rodrigues da Silva recentemente publicado, "Disputando espaço constituindo sentidos. Vivências, trabalho e embates na área da Manaus Moderna (Manaus - AM - 1967-2010) ${ }^{1}$ ” traz grande contribuição ao desvelar as disputas em torno dos projetos para Manaus desde a década de 1960 até o ano de 2010.

A autora perscrutou o desenvolvimento do "Projeto Manaus Moderna", que tinha o objetivo de modificar a capital do Amazonas, a partir da efetivação da Zona Franca de Manaus. Silva explica que dentro desse grande projeto de modificação da capital, houve atenção para a adequação do espaço às margens do Rio Negro, com a construção de Avenida Beira Rio - hoje denominada Avenida Lourenço da Silva Braga -, a construção da Feira Coronel Jorge Teixeira conhecida popularmente como a Feira da Manaus Moderna, e passagens de acesso entre a praia e a Avenida. Chama a atenção, pois o Projeto Manaus Moderna se estabelece a partir do caráter higienizador da Prefeitura de Manaus e do Governo do Estado do Amazonas, estes empenhados em dinamizar o transporte de material utilizado no Distrito Industrial que são descarregados na área portuária, e o desenvolvimento do comércio na área central da cidade.

Dentro das projeções do Governo do Estado do Amazonas para a área, as formas como estas adequações vão ganhando expressivas notas - às vezes de maneira ambígua - nos jornais diários da cidade, e nas denúncias e manifestações dos trabalhadores da Manaus Moderna é onde Silva vai delineando os contextos das disputas pelo espaço.

A obra de Silva se insere na concepção da História que, "procura entender o fazer-se dos homens, mulheres, crianças etc., e sua cultura, entendida como todo um modo de vida, ou

\footnotetext{
* Mestre em História pela Universidade Federal do Amazonas. E-mail: rafaelabastos.lds@ hotmail.com

${ }^{1}$ SILVA, Patrícia Rodrigues da. Disputando espaço constituindo sentidos. Vivências, trabalho e embates na área da Manaus Moderna (Manaus - AM - 1967-2010). Manaus: EDUA, 2016.
} 
seja, seus valores, tradições, esperanças, conflitos, perspectivas e práticas sociais ${ }^{2 \%}$, como propõe a autora, concepção esta que é inspirada em autores difundidos amplamente durante a década de 1980 nas Universidades brasileiras, como os ingleses Edward Palmer Thompson e Eric Hobsbawm preocupados em uma análise mais profícua em tornos dos sentidos e ações constituídos pelos trabalhadores, ampliando os diálogos das experiências dos sujeitos.

Patrícia Rodrigues da Silva com sensibilidade vai tecendo as análises a partir das narrativas dos trabalhadores da Manaus Moderna, aproximando do administrador da Feira Coronel Jorge Teixeira, professor (ex-camelô), carregadores, lojista, e moradores da região, aí encontra-se uma grande contribuição da autora para a historiografia regional que utiliza as fontes orais como ponto norteador para observar os conflitos, resistências dos trabalhadores mediante a imposição do Projeto Manaus Moderna sem nenhuma consulta pública, impactando a dinâmica do cotidiano de trabalhadores e moradores. A autora por meio das narrativas dos trabalhadores que lhes cederam entrevistas busca compreender os significados desses sujeitos a partir das experiências e memórias, apontando que a busca de significados não se refere a um caráter homogêneo das memórias e experiências construídas pelos sujeitos: “Assim, o sujeito se mostra, ao mesmo tempo, um ser individual e social ${ }^{3}$ ". Dentro dessa compreensão em torno dos significados e experiências dos indivíduos, Silva dialoga com referências importantíssimas das fontes orais e memória como, Alessandro Portelli ${ }^{4}$, Michael Pollak $^{5}$, Alistair Thomson ${ }^{6}$, que carregam em suas obras aspectos de como se forjam as memórias, e como elas estão carregadas de subjetividades, elemento de grande importância para a análise dos historiadores.

As disputas pelas memórias estavam também dentro das Instituições, onde Silva identifica um dos embates entre a Secretaria do Patrimônio Histórico e Artístico (SPHAN) que aponta uma série de problemas para a construção da Avenida Beira Rio (Avenida Lourenço da Silva Braga), observando que a mesma traria impactos prejudiciais ao prédio do

\footnotetext{
${ }^{2}$ SILVA, Patrícia Rodrigues da. Disputando espaço constituindo sentidos. Vivências, trabalho e embates na área da Manaus Moderna (Manaus - AM - 1967-2010), p. 16-17.

${ }^{3}$ SILVA, Patrícia Rodrigues da. Disputando espaço constituindo sentidos. Vivências, trabalho e embates na área da Manaus Moderna (Manaus - AM - 1967-2010), p. 42.

${ }^{4}$ PORTELLI, Alessandro. A filosofia e os fatos: narração, interpretação e significado nas memórias e nas fontes orais. Dossiê Tempo, Rio de Janeiro, v.1, n.2, p. 59-72, 1996.

Forma e significado na história oral: a pesquisa como um experimento de igualdade. Projeto História, São Paulo, Departamento de História da PUC/SP, n. 14, p. 07-24, fev. 1997. O momento em minha vida: funções do tempo na história oral. In: KHOURY, Yara Aun et al. Muitas memórias, outras histórias. São Paulo: Olho D’Água, 2004.

${ }^{5}$ POLLAK, Michael. Memória, Esquecimento, Silêncio. Revista de Estudos Históricos, Rio de Janeiro, vol. 2 , n. 3, 1989, p. 3-15.

${ }^{6}$ THOMSON, Alistair. Quando a memória é um campo de batalha: envolvimentos pessoais e políticos com o Exército Nacional. Projeto História, São Paulo, Departamento de História da PUC/SP, n 16, 1998.
} 
Mercado Municipal Adolpho Lisboa, e aos trabalhadores e moradores das proximidades, ponto que o Governo do Estado, como executor do Projeto e a Prefeitura de Manaus elaborador do Projeto não consideraram, pois para estes, as adequações feitas estavam alinhadas com o desenvolvimento urbano e econômico previstos no Projeto. Silva vai mais afundo quando analisa que mesmo que a SPHAN tenha suas justificativas nos embargos feitos à obra, esta deixa a desejar ao buscar o entendimento genérico de Patrimônio, idealizando o histórico a partir das "edificações, o meio físico", e não inserindo preocupação ao que tange "aos anseios e demandas de moradores e usuários do espaço". O entendimento de "patrimônio esvaziado" destacada no livro para a SPHAN advém das reflexões que a autora tem a partir da concepção de Nestor García Canclini, no que este chama de tradicionalismo substancialista, onde Canclini critica esta noção de que "patrimônio está constituído por um modo de formas excepcionais, onde não contam as condições de vida e trabalho de quem os produziu ${ }^{7}$ ".

O papel dos jornais no período do Projeto Zona Franca de Manaus é constantemente na obra uma ponta de lança para análise do quanto os jornais como o A Crítica, apoiador do Projeto Zona Franca de Manaus, e de vários projetos que vão se desenvolvendo paralelo às normativas do capitalismo, se atrelando ao discurso do Estado e da elite quanto às modificações da área da Manaus Moderna reforçando o caráter saneador e de desenvolvimento econômico, mesmo que por vezes, aponte os problemas que o projeto vai causando para os trabalhadores e moradores. O Jornal A Crítica em várias notas corrobora os aspectos higienizadores, como atenta Silva para a legenda de uma das fotos do A Crítica, 13 de Agosto de 1980, "consumada a limpeza da escadaria", em referência a retirada dos comerciantes. O jornal "A Notícia" de circulação diária inaugurado no período da Ditadura Militar expunham em suas páginas a retirada dos moradores da cidade Flutuante, na Escadaria dos Remédios com a seguinte notícia no dia 11 de Agosto de 1980: "Capitania e prefeitura acabam hoje com a "vergonha" da escadaria dos Remédios".

Destacam-se como referências metodológicas para análises das matérias jornalísticas, as obras da historiadora Heloísa de Faria Cruz, que se direciona a abordar a cultura letrada e o viver urbano, no sentido de que a imprensa é uma "prática social e momento de constituição /instituição dos modos de viver e pensar ${ }^{8}$ " em São Paulo nos fins do século XIX e início do XX. A historiadora Maria Luiza Ugarte Pinheiro, também é uma grande contribuição para

\footnotetext{
7 CANCLINI, Nestor García. O patrimônio cultural e a construção imaginária do nacional. Revista do Patrimônio Histórico e Artístico Nacional, Rio de Janeiro, IPHAN, n.23, p. 95-115, 1994.

${ }^{8}$ CRUZ, Heloísa de Faria. São Paulo em papel e tinta: periodismo e vida urbana - 1980-1915. São Paulo: Edusc, 2000 .
} 
Silva, pois Ugarte coloca a imprensa como possibilidade de aprender "múltiplas dimensões do viver social $^{9 ”,}$, no Amazonas nos fins do século XIX e início do XX.

Com muito esmero a autora se debruça em analisar as fotografias a partir de referências como Boris Kossoy ${ }^{10}$ e Pilippe Dubois ${ }^{11}$. Silva menciona que a fotografia, "sendo uma produção cultural, carrega elementos da subjetividade e requer um trato específico, uma reflexão sobre a natureza e a forma como deve ser tratada dentro do trabalho, como quaisquer fontes que possamos utilizar". Neste sentido, a obra segue destacando a atenção para as fotografias expostas nos jornais, publicadas na internet, revistas e acervo pessoal de alguns feirantes, e algumas publicadas em livros de memorialistas. Silva denota que as fotografias oriundas da imprensa devem ser "compreendidas como força atuante na configuração e difusão da notícia ${ }^{12}$, e inspirada em Gisèle Freund $^{13}$ - autora que metodologicamente sobre o uso das fotografias dispostas em jornais - aponta que o fotojornalismo funciona a partir de interesses, se convertendo em meio de propaganda e manipulação.

Silva sinaliza que os usos de termos como "limpar" significava o "esvaziamento dos modos de viver e morar naquela espacialidade ${ }^{14}$,. Esses termos eram percebidos pelos entrevistados que apontavam os momentos que foram expulsos os camelôs e feirantes, e as maneiras como eram identificados pelos jornais, autoridades e parte da sociedade manauara como "responsáveis pelas falta de estrutura da feira", "foco de doenças como a cólera", articulando um sentido pejorativo para a favela, e "a favela como lugar de não trabalho". A polícia muitas vezes, como mostra a obra de Silva, vai participar das retiradas de trabalhadores e moradores da área, e novamente, atentos aos modos que são pensados pelas autoridades, tanto os camelôs quanto os feirantes apanhavam da polícia, eram perseguidos e reprimidos com a apreensão de mercadorias - violência que se agravou com a chegada de Arthur Virgílio Neto à Prefeitura de Manaus, em 1989. Em alguns momentos, a "guerra do lugar", como Silva chama a disputa pela espacialidade se relacionava às demandas dos atacadistas que eram defendidos pelos jornais como grupos importantes ao abastecimento da cidade, sendo defendidos, também, pela Secretaria Municipal de Abastecimentos, Marcados e

\footnotetext{
${ }^{9}$ PINHEIRO, Maria Luiza Ugarte. Folhas do Norte: letramento e periodismo no Amazonas (1890-1920). 2001. Tese (Doutorado em História) Pontifícia Universidade Católica de São Paulo, São Paulo, 2001.

${ }^{10}$ KOSSOY, Boris. Os tempos da fotografia: o efêmero e o perpétuo. Cotia, SP: Ateliê, 2007.

${ }^{11}$ DUBOIS, Philippe. O ato fotográfico. Campinas, SP: Papirus, 1993. (Série Ofício de Arte e Forma).

12 SILVA, Patrícia Rodrigues da. Disputando espaço constituindo sentidos. Vivências, trabalho e embates na área da Manaus Moderna (Manaus - AM - 1967-2010), p. 37.

${ }^{13}$ FREUND, Gisèle. La fotografia como documento social. Barcelona: Gustavo Gilli, 2008.

${ }^{14}$ SILVA, Patrícia Rodrigues da. Disputando espaço constituindo sentidos. Vivências, trabalho e embates na área da Manaus Moderna (Manaus - AM - 1967-2010), p. 238.
} 
Feiras - SEMAF ${ }^{15}$, que disponibilizava para os atacadistas boxes da feira, quando na verdade, eram destinados aos permissionários, "Lei Municipal n¹23, de 25 de novembro de 2004". As possibilidades encontradas das narrativas dos trabalhadores e moradores da área da Escadaria dos Remédios e da Cidade Flutuante constituíram significados para suas experiências individuais e aquelas que foram compartilhadas socialmente, interpretando as práticas e sentidos que fiscais da feira adotavam com os empresários, compactuando se não com a retirada de uma só vez dos trabalhadores e moradores, aos menos, tinham aprendido a fazer de outras maneiras, como ceder o espaço que daria para três ou quatro permissionários para um empresário. Alessandro Portelli nos direciona à reflexão da importância da subjetividade, da reflexão, e da trajetória que segue a memória do entrevistado,

Pois, não só a filosofia vai implícita nos fatos, mas a motivação para narrar consiste precisamente em expressar o significado da experiência através dos fatos: recordar e contar já é interpretar. A subjetividade, o trabalho através do qual as pessoas constroem e atribuem o significado à própria experiência e à própria identidade, constitui por si mesmo o argumento, o fim mesmo do discurso. Excluir ou exorcizar a subjetividade como se fosse somente uma fastidiosa interferência na objetividade factual do testemunho quer dizer, em última instância, torcer o significado próprio dos fatos narrados ${ }^{16}$.

A memória de muitos trabalhadores ficou marcada pela exclusão, pela a perda total ou quase total de suas mercadorias e de seus rendimentos, mesmo depois de deslocados para outras feiras que ficavam em áreas distantes do Centro dificultando que os trabalhadores tivessem contato com os clientes antigos e tivessem vigor em suas vendas. Quando podiam comprar suas mercadorias, e quando podiam contar com outros trabalhadores, os feirantes articulavam o retorno à Manaus Moderna, reivindicando direitos e denunciando as manobras das Secretarias ligadas à Prefeitura para atender as demandas de empresários. Os sujeitos que vivenciaram os momentos de lutas, e tiveram suas barracas/casas destruídas pelo poder público, e depois por um incêndio ocorrido em 1991, nas entrevistas contidas no livro revelam memórias sobre a violência que viveram com a perda do espaço de trabalho, da sobrevivência, e o surgimento de necessidades que começam ou pioram ao enfrentarem o fim de seus modos de vida.

A continuidade do Projeto Manaus Moderna ficou sob responsabilidade, em 1993, do prefeito Amazonino Mendes, que Silva vai identificar como político que desperta admiração de vários trabalhadores, pois oferece boxes da feira Coronel Jorge Teixeira aos feirantes, mas

\footnotetext{
15 SILVA, Patrícia Rodrigues da. Disputando espaço constituindo sentidos. Vivências, trabalho e embates na área da Manaus Moderna (Manaus - AM - 1967-2010), p.277. Esse aspecto, é mencionado por um entrevistado de Silva, no sentido de que o entrevistado ciente da Lei existente não se conforma com as práticas da SEMAF.

${ }^{16}$ PORTELLI, Alessandro. A filosofia e os fatos: narração, interpretação e significado nas memórias e nas fontes orais. Dossiê Tempo, Rio de Janeiro, v.1, n.2, 1996, p. 60.
} 
não abrange a todos que foram retirados anteriormente. Ao tempo que alguns dos entrevistados de Silva guardam fotos de Amazonino, ou atribuem ao ato dele chamar os feirantes aos boxes da Manaus Moderna como um ato de solidariedade aos trabalhadores, outros atribuem a ele outro significado, como um político que usa as necessidades alheias para conseguir votos.

As tensões sobre a espacialidade da Manaus Moderna ganham novos contornos, novos sujeitos se estabelecem enquanto trabalhadores, a espacialidade vai entre alguns anos sendo modificada. A obra de Patrícia Rodrigues da Silva nos leva aos mundos de possibilidades de projetos permeados de disputas, e os trabalhadores estão inseridos enquanto construtores de projetos para a área portuária, afinal, suas resistências como permanecerem, voltarem, reivindicarem marcam também o quanto os trabalhadores e moradores não estavam dispostos a serem engolidos por planos alheios às suas expectativas, às suas experiências, as redes de sociabilidades e principalmente às suas memórias. 